conservation tool. For instance, should it really be necessary even if it were possible - to put a dollar value on a stable climate or predictable tides?

At best it seems likely that conventional market economics will continue to foster corruption and greed, both enemies of conservation. Much more worrying, economic growth - a central pillar of all national economies - is itself patently unsustainable on a finite planet. This is an issue that no one can afford to ignore - least of all environmental economists.

Moreover, many biodiversity problems are now international and subject to the vagaries of the international political agenda. International debt is widely recognized as extremely damaging to the interests of conservation but is barely discussed in the book and the General Agreement on Tariffs and Trade (GATT, which could also become a huge obstacle in the path of achieving sustainable management of wildlands) rates not a single mention.

On balance, the authors do make a convincing case - that wild life managers cannot afford to ignore economics and that economists must incorporate the true values of wildlife and biodiversity into local and national economic and land-use planning. They also make a strong and sensible case for local involvement in all wildlife management projects.

From the conservationist's (as opposed to the economist's) perspective much the most stimulating chapter is that written by Timothy Swanson with Richard Luxmoore, Director of the Wildlife Trade Monitoring Unit of the World Conservation Monitoring Centre. This chapter reviews the wide range of intensities and types that wildlife use can encompass, considers the conservation and economic consequences of domestication, captive breeding, ranching and wild harvesting and concludes, perhaps unsurprisingly, that the less intensive forms of management are the most likely to succeed.

Unfortunately, the typographical errors that pepper the book reach ludicrous quantities in this chapter. It is hard to imagine how so many errors there are dozens - can have been allowed to remain.

Overall this is a worthy book on an important subject, sadly marred by a somewhat blinkered approach and very poor editing.

Mike Read

FFPS Botanical Consultant

\section{The Global Status of} Peatlands and their Role in Carbon Cycling. A report for Friends of the Earth by the Wetland Ecosystem Research Group, Department of Geography, University of Exeter, C.P. Immirzi and E. Maltby with R. S. Clymo (Friends of the Earth, London, 1992, ISBN 1857501055 , 145 pp., SB £17)

This authoritative and substantial report examines the past, present and potential future role of peatlands in the global cycling of carbon. The main body of the report consists of eight sections, and starts with a review of the various definitions and classifications of peat (Section 1), the processes and dynamics of peat formation (Section 2), and the global extent of peatlands (Section 3). The global impact of agriculture, forestry and extraction of peat for fuel and horticultural use, is extensively documented in sections 4 and 5 . The last three sections consider the role of peatlands as a source and sink of carbon dioxide and methane. The report's findings are presented in an executive summary.

The report concludes that despite their relatively small global area, about 397 million hectares ( 3 per cent of the earth's surface), peatlands have played and will continue to play an important role in global cycling of carbon. Under natural conditions mires are capable of sequestering 2.25 tonnes of carbon per hectare. Although their ability to sequester carbon decreases with age, they continue to function as long-term carbon sinks. The report estimates that peatlands contain between 329 and 528 billion tonnes of carbon, about three times the size of the carbon pool associated with tropical rain forests. However, with disturbance and drainage, carbon, which has accumulated over millennia, is rapidly released, converting peatlands from a carbon sink into a significant carbon source. It is abundantly clear from the information presented in this report that peatland should not be disturbed and where possible water levels should be maintained.

These conclusions are supported by a rigorous and critical assessment of published material. The assumptions and basis used by the authors to assess the extent and magnitude of carbon fluxes associated with peatlands are explicitly stated and justified. The authors avoid making excessive or unsubstantiated claims in the report, which is well written and contains a wealth of information on the global status of a natural habitat that receives remarkably little effective protection. They highlight the lack of data on the extent of tropical peats, which are being rapidly exploited throughout the developing world.

Steve Waite Brighton University 